\title{
Comparative evaluation of femtosecond laser- assisted cataract surgery and conventional phacoemulsification in white cataract
}

This article was published in the following Dove Press journal:

Clinical Ophthalmology

22 July 2016

Number of times this article has been viewed

\author{
Jeewan S Titiyal \\ Manpreet Kaur \\ Archita Singh \\ Tarun Arora \\ Namrata Sharma
}

Cornea, Cataract \& Refractive Surgery Services, Dr Rajendra Prasad Centre for Ophthalmic Sciences, All India Institute of Medical Sciences, New Delhi, India
Correspondence: Jeewan S Titiyal

Cornea, Cataract and Refractive Surgery Services, Dr Rajendra Prasad Centre for Ophthalmic Sciences, All India Institute of Medical Sciences, Ansari Nagar, New Delhi I I0029, India

Tel +9| II 26593 | 46

Email titiyal@gmail.com
Purpose: To compare femtosecond laser-assisted capsulotomy with conventional manual capsulorhexis in cases of white cataract.

Patients and methods: The prospective comparative study enrolled 80 eyes ( 80 patients) with white cataract that underwent either femtosecond laser-assisted cataract surgery (Group I, $\mathrm{n}=40$ ) or conventional manual phacoemulsification (Group II, $\mathrm{n}=40$ ) at a tertiary care ophthalmic institution. The groups were divided based on the patient's choice and affordability of the procedure. Capsulotomy/capsulorhexis was evaluated in terms of size, circularity index (4П [area/perimeter $\left.{ }^{2}\right]$ ), intraocular lens coverage, and continuity. Each group was further subdivided based on the release of white milky fluid on initiation of the capsulotomy/capsulorhexis, and the "fluid" cases were compared with the "no-fluid" cases. The primary outcome measure was capsulotomy/capsulorhexis characteristics in the two groups. The secondary outcome measures were intraoperative phacoemulsification parameters, intraoperative complications, and postoperative visual acuity.

Results: The size of the capsulotomy/capsulorhexis was $4.9 \pm 0.1 \mathrm{~mm}$ in Group I and $5.3 \pm 0.4 \mathrm{~mm}$ in Group II $(P<0.001)$. Mean circularity index was $0.996 \pm 0.003$ and $0.909 \pm 0.047$ in Groups I and II, respectively $(P<0.001)$. In Group I, free-floating circular capsulotomies were obtained in $52.5 \%(21 / 40)$ eyes; $37.5 \%(15 / 40)$ eyes had microadhesions; and $10 \%$ (4/40) eyes had incomplete capsulotomy in 1-2 clock hours. The incidence of residual adhesions was more in cases with release of white milky fluid ( $P=0.003$ ). In Group II, a multistep capsulorhexis was performed in $70 \%(28 / 40)$ of the eyes. There was no difference in terms of visual outcomes and intraoperative complications.

Conclusion: Femtosecond laser-assisted cataract surgery has the advantage of creating a circular and optimally sized capsulotomy in cases of white cataract. The release of white milky fluid during femtosecond laser delivery is the most important factor affecting the creation of a free-floating capsulotomy.

Keywords: femtosecond laser-assisted cataract surgery, white cataract, conventional phacoemulsification, capsulorhexis

\section{Introduction}

Femtosecond laser-assisted cataract surgery (FLACS) is superior to conventional phacoemulsification in terms of precise wound construction, capsulotomy, intraocular lens (IOL) centration, and decreased effective phacoemulsification time. ${ }^{1-4}$ FLACS is comparable to traditional cataract surgery in terms of intraoperative complications, although further research is needed to evaluate its long-term safety aspects. ${ }^{5-7}$ It may be especially advantageous in white cataracts, where achieving an adequately sized continuous curvilinear capsulorhexis is the major surgical challenge. 
The increased incidence of capsulorhexis-related complications in white cataracts is often associated with posterior capsular rent, vitreous loss, and nucleus drop. ${ }^{8}$ Various maneuvers have been used to facilitate capsulorhexis, such as use of high-molecular-weight viscoelastic, ${ }^{9}$ trypan blue dye to stain the anterior capsule, ${ }^{10}$ two-stage capsulorhexis, ${ }^{11}$ frequent aspiration of liquefied cortical matter, ${ }^{12}$ use of Vannas scissors, ${ }^{12}$ and endoilluminator. ${ }^{9}$ However, limited literature exists on the application of femtosecond lasers in white cataracts. ${ }^{13}$ Comparative evaluation of FLACS and conventional phacoemulsification has been done for varying grades of nuclear sclerosis; however, there are no studies that have compared the outcomes of FLACS with conventional phacoemulsification in cases with white cataract. 5,7

We herein report our results of comparison of femtosecond laser capsulotomies with conventional capsulorhexis in cases of white cataract.

\section{Patients and methods}

In this prospective comparative study, 80 eyes of 80 patients with white cataract were enrolled at Dr RP Centre for Ophthalmic Sciences, All India Institute of Medical Sciences, New Delhi, India. The study conformed to the tenets of the Declaration of Helsinki. Ethical clearance was obtained from the All India Institute of Medical Sciences institutional review board.

Informed consent was obtained from all patients. The white cataracts were classified into Type I, II, and III according to the classification provided by Brazitikos et al. ${ }^{8}$ Type I intumescent, white cataracts are characterized by the presence of liquefied cortex, Type II white cataracts have a voluminous nucleus with little amount of solid white cortex, and Type III white cataracts have anterior capsule fibrosis. Type I and Type II cataracts were included in the study. Type III white cataracts with calcific and fibrotic capsules were excluded from the study. ${ }^{8}$ Eyes with preexisting glaucoma, retinal pathology, pseudoexfoliation syndrome, or pupillary dilatation $<6 \mathrm{~mm}$ were also excluded. The patients were divided into two groups, each consisting of 40 eyes (40 patients). Group I $(n=40)$ underwent FLACS and Group II $(n=40)$ underwent conventional phacoemulsification performed by an experienced phacoemulsification surgeon (JST). The patients with white cataract scheduled to undergo FLACS or conventional phacoemulsification (based on patient's choice and affordability of the procedure) were compared. Randomization was not done in the study. The preoperative detailed examination included uncorrected distance visual acuity (UDVA), anterior segment evaluation, slit-lamp biomicroscopy, applanation tonometry, biometry (Tonoref III, Nidek Co., Ltd. and OcuScan RxP, Alcon Laboratories, Inc.), and ultrasonography B-scan (Master-Vu ophthalmic ultrasound, Sonomed Escalon). The primary outcome measure was capsulotomy/capsulorhexis characteristics in the two groups. The secondary outcome measures were intraoperative phacoemulsification parameters, intraoperative complications, and postoperative visual acuity.

\section{Surgical technique}

In Group I, the preoperative planning of the corneal incisions, capsulotomy, and nucleotomy was done on LenSx version 2.23 femtosecond laser system (Alcon LenSx, Inc., Aliso Viejo, CA, USA). A $4.9 \mathrm{~mm}$ capsulotomy was planned, with a $2.2 \mathrm{~mm}$ temporal clear corneal incision and two $1.1 \mathrm{~mm}$ side ports at $90^{\circ}$ and $240^{\circ}$. The chop pattern of nucleotomy was selected, with three chops of length $6 \mathrm{~mm}$ each. The posterior offset was kept at $800 \mu \mathrm{m}$. Successful dock was achieved using a SoftFit ${ }^{\mathrm{TM}}$ (Alcon Laboratories, Inc., California) applanating patient interface. The anterior segment structures were imaged with intraoperative optical coherence tomography and the planned treatment was verified. The femtosecond laser parameters were the same as those used in our routine cases (nonwhite cataract cases) of FLACS. The energy was kept at $6 \mu \mathrm{J}$ for corneal incisions, $8 \mu \mathrm{J}$ for capsulotomy, and $12 \mu \mathrm{J}$ for nucleotomy. The spot and layer separation was $5 \mu \mathrm{m}$ for the side port incisions, $6 \mu \mathrm{m}$ for $2.2 \mathrm{~mm}$ corneal incision, and $14 \mu \mathrm{m}$ for the nucleotomy. For capsulotomy, the spot separation was $5 \mu \mathrm{m}$, the layer separation was $4 \mu \mathrm{m}$, and the anterior and posterior delta value was $350 \mu \mathrm{m}$ each.

After femtosecond laser application, the corneal incisions were opened with the help of flap lifter. Sodium hyaluronate $1 \%$ was injected to maintain the anterior chamber and trypan blue $0.06 \%$ (VisionBlue ${ }^{\circledR}$, DORC International, the Netherlands) was injected to stain the anterior capsule. The capsulotomies were lifted and removed with the microcapsulorhexis forceps, and microadhesions, if any, were released (Figure 1, Video S1). Gentle hydrodissection was performed, followed by phacoemulsification, irrigation-aspiration (IA), and implantation of single-piece hydrophobic acrylic IOL. A hybrid technique of IA using a combination of coaxial and bimanual IA hand pieces was frequently employed to aspirate the subincisional cortical matter in cases with difficulty during removal of cortical matter. ${ }^{14}$ The corneal wounds were hydrated at the end of the procedure.

In Group II, a 2.2 keratome was used to construct a temporal corneal incision and two side ports were constructed using a $20 \mathrm{G}$ microvitreoretinal blade. The anterior capsule 

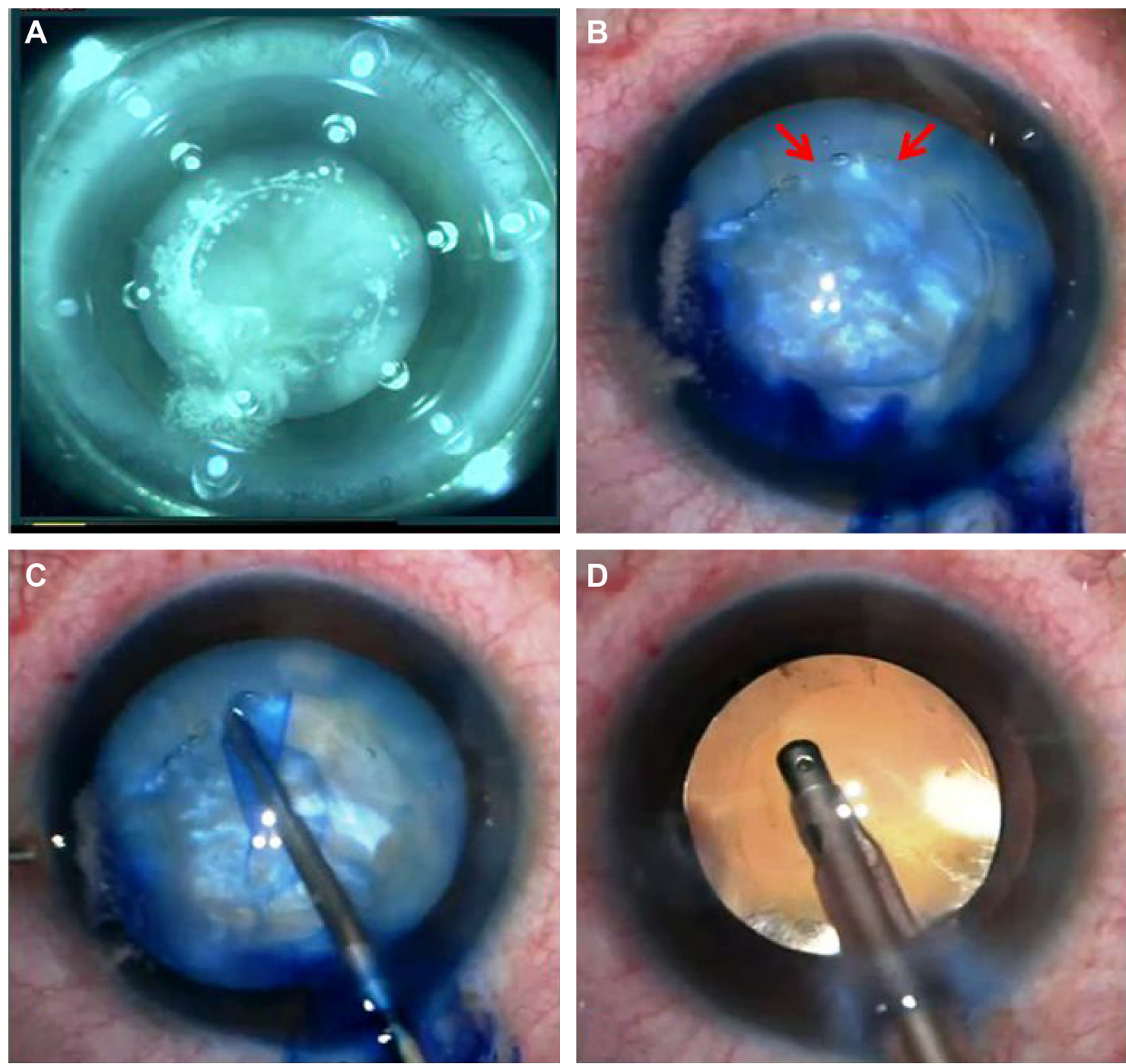

Figure I FLACS in a case of white cataract.

Notes: (A) Explosive egress of milky white fluid on initiation of femtosecond laser capsulotomy in a case undergoing FLACS. (B) Trypan blue stained femtosecond laser capsulotomy (arrows: area of incomplete capsulotomy). (C) Circumferential completion of capsulotomy with release of adhesions using microcapsulorhexis forceps. (D) Circular, well-centered, optimally sized capsulotomy with $360^{\circ} \mathrm{IOL}$ coverage.

Abbreviations: FLACS, femtosecond laser-assisted cataract surgery; IOL, intraocular lens.

was stained with trypan blue dye $0.06 \%$ under $1 \%$ sodium hyaluronate. Capsulorhexis was performed with a 26-gauge needle cystotome; microcapsulorhexis forceps was used if required. In cases with intumescence, an initial smaller capsulorhexis was followed by the aspiration of liquefied cortex, thus decreasing the raised intralenticular pressure. Subsequently, the capsulorhexis was enlarged to an adequate size (Figure 2). The intended width of the capsulorhexis was $\sim 5 \mathrm{~mm}$. The aim was to provide $\sim 0.5 \mathrm{~mm}$ IOL coverage all around as the optic of the IOL was $6 \mathrm{~mm}$. Gentle hydrodissection was performed and phacoemulsification was completed. After IOL implantation, the capsulorhexis was further enlarged if required to achieve an adequate size. The corneal wounds were hydrated at the end of the procedure.
Intraoperatively, the total surgical time, cumulative dissipated energy, total ultrasound time, and total aspiration time were noted. Intraoperative complications such as anterior capsular tears/extension, posterior capsular tears, vitreous loss, need for anterior vitrectomy, and inability to implant IOL were noted. Postoperatively, clinical photographs were captured with the help of slit-lamp-mounted camera on postoperative day 30 and after 6 months, and the capsulorhexis size, shape, continuity, and IOL optic coverage were evaluated. Image-processing software (ImageJ 1.46r, National Institutes of Health, MD, USA) was used to measure the diameter of the capsulorhexis and calculate the circularity index. The diameter of the implanted IOL was used as a scale to calibrate the image. The circularity 

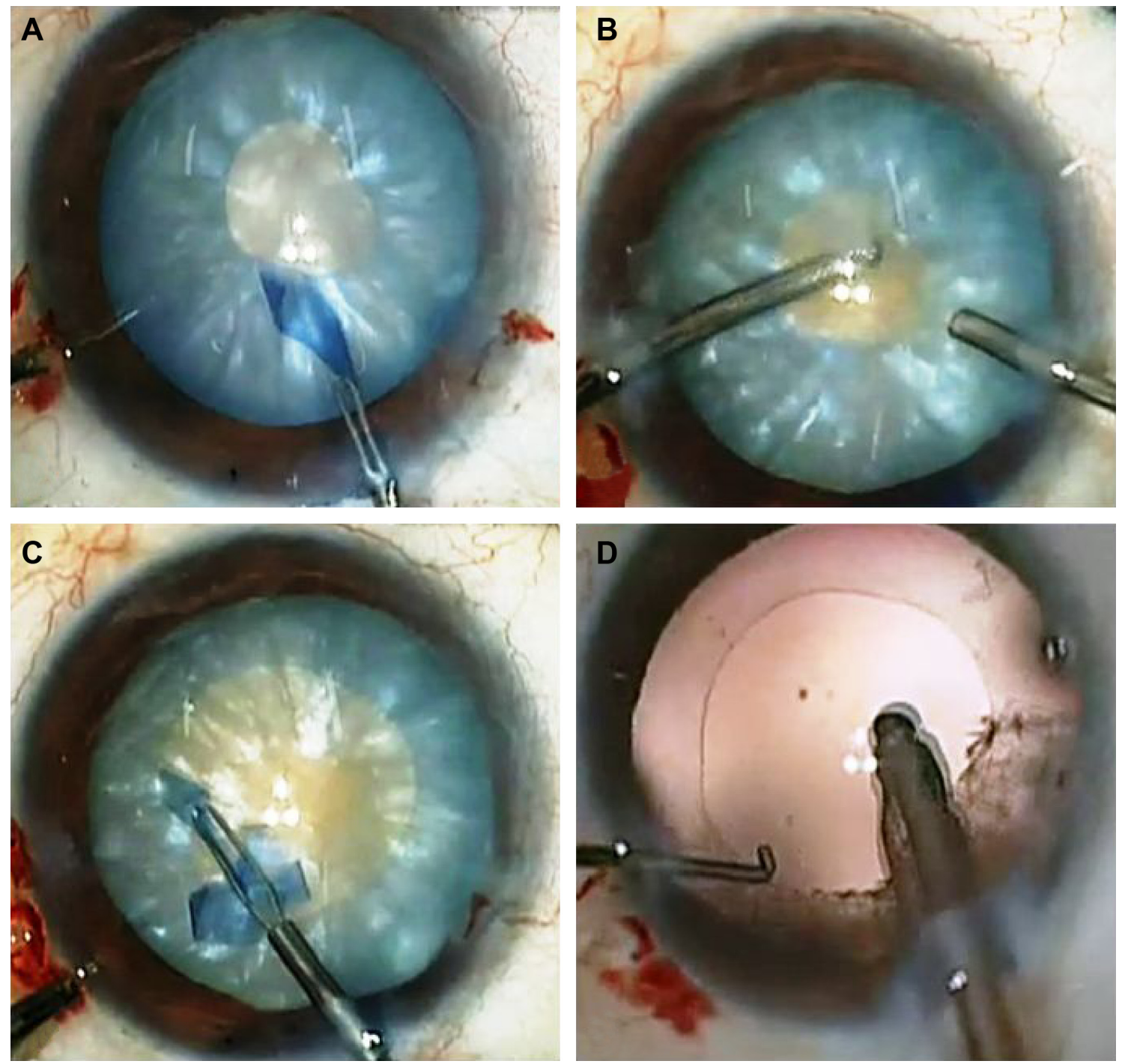

Figure 2 Conventional phacoemulsification in a case of white cataract.

Notes: (A) Initial small capsulorhexis in a case of intumescent white cataract undergoing conventional phacoemulsification. (B) Aspiration of liquefied cortex to decrease intralenticular pressure. (C) Secondary enlargement of capsulorhexis to desired size. (D) Centered optimal sized capsulorhexis.

index was used to assess the shape of the capsulotomy. The circularity index was given by the formula $4 \Pi$ (area/ perimeter ${ }^{2}$ ) and a circularity index of 1 implied a perfect circle. ${ }^{3}$ The IOL centration and coverage was assessed on the basis of coverage of IOL optic in all four quadrants by the capsulotomy/capsulorhexis margin. Continuity of the capsulorhexis refers to the absence of radial extension/tear of the capsulorhexis edge. UDVA and corrected distance visual acuity (CDVA) were assessed on postoperative day 30 and at 6 months.

\section{Statistical analysis}

Statistical analysis was done using Statistical Package for the Social Sciences (SPSS 11.0; SPSS Inc., Chicago, IL, USA). Normally distributed continuous variables were expressed as mean \pm standard deviation and were compared using independent samples $t$-test. Non-normally distributed continuous variables were compared using Mann-Whitney $U$-test. Nominal data were compared using chi-square test or Fisher's exact test as appropriate. A $P$-value less than 0.05 was considered significant.

\section{Results}

The demographic characteristics of the cases are summarized in Table 1. The mean age of the patients was 62.9 \pm 9.1 years in Group I and 64.8 \pm 8.3 years in Group II $(P=0.34)$. Group I consisted of 20 males and 20 females; Group II had 17 males and 23 females.

A continuous capsulotomy/capsulorhexis was achieved in $97.5 \%$ (39/40) of eyes, each in Groups I and II. Anterior capsular extension with radial tear was observed in one eye in each group. 
Table I Comparison of demographic characteristics between Group I (FLACS) and II (conventional phacoemulsification)

\begin{tabular}{|c|c|c|}
\hline $\begin{array}{l}\text { Demographic } \\
\text { characteristics }\end{array}$ & $\begin{array}{l}\text { Group I } \\
\text { (n=40; FLACS) }\end{array}$ & $\begin{array}{l}\text { Group II } \\
\text { ( } n=40 ; \text { conventional } \\
\text { phacoemulsification) }\end{array}$ \\
\hline Age (mean $\pm S D)$ & $62.9 \pm 9.1$ years & $64.8 \pm 8.3$ years \\
\hline Sex & $\begin{array}{l}20 \text { males } \\
20 \text { females }\end{array}$ & $\begin{array}{l}17 \text { males } \\
23 \text { females }\end{array}$ \\
\hline $\begin{array}{l}\text { Number of cases with } \\
\text { release of white milky fluid }\end{array}$ & 17 & 19 \\
\hline $\begin{array}{l}\text { Number of cases without } \\
\text { release of white milky fluid }\end{array}$ & 23 & 21 \\
\hline
\end{tabular}

Abbreviations: FLACS, femtosecond laser-assisted cataract surgery; SD, standard deviation.

Four patterns of femtosecond laser capsulotomies have been described by Nagy et al ${ }^{15}$ - Type I (free floating), Type II (microadhesions; ie, an area of complete cut mixed with minute areas of adhesions), Type III (incomplete treatment pattern - no visible femtosecond laser cut in the anterior capsule), and Type IV (irregular complete pattern). In Group I, free-floating capsulotomies (Type I) were achieved in 52.5\% (21/40) of eyes. However, $47.5 \%$ (19/40) of eyes needed manual completion of the capsulotomy, of these 37.5\% (15/40) had microadhesions (Type II capsulotomy) and 10\% (4/40) had incomplete area of capsulotomy in 1-2 clock hours (Type III capsulotomy). In Group II, a multistep capsulorhexis was performed in $70 \%(28 / 40)$ cases. The mean diameter of the capsulotomy/capsulorhexis was $4.9 \pm 0.1 \mathrm{~mm}$ in Group I and $5.3 \pm 0.4 \mathrm{~mm}$ in Group II $(P<0.001$, difference $0.39 ; 95 \%$ confidence interval $[\mathrm{CI}]$ : $0.27,0.52)$. The mean circularity index was $0.996 \pm 0.003$ in Group I and $0.910 \pm 0.047$ in Group II ( $P$-value $<0.001$, difference: 0.09 [95\% CI: 0.07, 0.10]). Inadequate coverage of IOL by the capsulotomy/capsulorhexis edge was noted in 7.5\% (3/40) cases in Group I and $12.5 \%(5 / 40)$ cases in Group II $(P=0.712)$. At 6 months, the mean diameter of the capsulotomy/capsulorhexis was $4.9 \pm 0.1 \mathrm{~mm}$ in Group I and $5.3 \pm 0.4 \mathrm{~mm}$ in Group II $(P<0.001$, difference: 0.37 [95\% CI: $0.25,0.50])$. The mean circularity index was $0.991 \pm 0.023$ in Group I and $0.910 \pm 0.047$ in Group II ( $P$-value $<0.001$, difference: 0.08 [95\% CI: 0.06, 0.10]).
The cumulative dissipated energy, total ultrasound time, total aspiration time, and total surgical time were comparable between the two groups (Table 2).

There was no case of posterior capsular rent, vitreous loss, nucleus drop, or inability to implant IOL in Group I or II. The mean logarithm of the minimum angle of resolution (logMAR) UDVA was $0.128 \pm 0.122$ in Group I and $0.115 \pm 0.127$ in Group II $(P=0.655)$ at 1 month postoperatively. The mean $\log$ MAR CDVA was $0.010 \pm 0.044$ in Group I and $0.015 \pm 0.053$ in Group II $(P=0.649)$ at 1 month postoperatively. At 6 months, mean $\log$ MAR UDVA was $0.13 \pm 0.12$ in Group I and $0.10 \pm 0.12$ in Group II $(P=0.315)$. At 6 months, mean logMAR CDVA was $0.005 \pm 0.031$ in Group I and $0.010 \pm 0.044$ in Group II $(P=0.562)$.

The white cataracts in each group were divided into two subgroups based on the release of white milky fluid on initiation of the capsulotomy/capsulorhexis. The assessment of milky fluid egress was qualitative, and no attempt was made to quantify the amount of fluid by the surgeon. In Group I, 17 cases had release of white milky fluid (subgroup A) and 23 cases did not (subgroup B). In Group II, 19 cases were in the fluid group (subgroup A) and 21 cases were in the nofluid group (subgroup B). The capsulotomy/capsulorhexis characteristics in the "fluid" cases were compared with the "no-fluid" cases in each group.

\section{Capsulotomy characteristics in cases with "fluid" and "no-fluid" in Group I}

Continuous capsulotomies were achieved in $94.1 \%(16 / 17)$ cases with fluid and $100 \%(23 / 23)$ cases with no-fluid $(P=0.42)$.

In the cases with fluid, free-floating (Type I capsulotomy) capsulotomies were achieved in 23.5\% (4/17) cases. Manual completion of the capsulotomy was needed in $76.5 \%$ $(13 / 17)$ cases, of these $52.9 \%(9 / 17)$ had microadhesions (Type II capsulotomy) and 23.5\% (4/17) had incomplete area of capsulotomy in 1-2 clock hours (Type III capsulotomy).

Table 2 Comparison of phacoemulsification parameters between Group I (FLACS) and II (conventional phacoemulsification)

\begin{tabular}{llllc}
\hline Phacoemulsification parameter & $\begin{array}{l}\text { Group I (FLACS) } \\
\text { (mean } \pm \text { SD) }\end{array}$ & $\begin{array}{l}\text { Group II (conventional } \\
\text { phacoemulsification) (mean } \pm \text { SD) }\end{array}$ & Difference (95\% Cl) & P-value \\
\hline Cumulative dissipated energy (seconds) & $18.1 \pm 11.5$ & $21.0 \pm 10.9$ & $-2.9(-7.8,2.1)$ & 0.25 \\
Total ultrasound time (seconds) & $68.4 \pm 34.0$ & $78.4 \pm 33.4$ & $-10.0(-25.0,5.0)$ & 0.19 \\
Total aspiration time (seconds) & $340.1 \pm 73.7$ & $308.0 \pm 76.5$ & $32.1(-1.3,65.6)$ & 0.06 \\
Total duration of surgery (minutes) & $15.7 \pm 3.3$ & $14.9 \pm 3.0$ & $0.9(-5.0,2.3)$ & 0.207 \\
\hline
\end{tabular}

Notes: Independent samples $t$-test was applied. A $P$-value $<0.005$ was considered significant.

Abbreviations: FLACS, femtosecond laser-assisted cataract surgery; SD, standard deviation; $\mathrm{Cl}$, confidence interval. 
In cases with no-fluid, free-floating capsulotomies were achieved in $73.9 \%(17 / 23)$ cases. Approximately $26.1 \%$ (6/23) of eyes needed manual completion of the capsulotomy and release of the microadhesions (Type II capsulotomy). There was no case with incomplete capsulotomy. The incidence of residual adhesions and incomplete capsulotomies was significantly more in cases with release of white milky fluid $(P=0.003)$.

Anterior capsular extension with radial tear was observed in one eye in fluid release group only $(P=0.42)$. The mean diameter of the capsulotomy was $4.9 \pm 0.1 \mathrm{~mm}$ in fluid and no-fluid group $(P=0.9)$. The mean circularity index was $0.996 \pm 0.003$ in the fluid group and $0.997 \pm 0.003$ in the no-fluid group $(P=0.1)$. Inadequate coverage of IOL by the capsulotomy edge was noted in $17.6 \%(3 / 17)$ cases in fluid group only $(P=0.09)$.

\section{Capsulorhexis characteristics in cases with "fluid" and "no-fluid" in Group II}

A continuous capsulorhexis was achieved in 100\% (19/19) cases with fluid and $95.2 \%(20 / 21)$ cases with no-fluid $(P=1.0)$.

A multistep capsulorhexis was performed in $84.2 \%$ $(16 / 19)$ cases with fluid and $57.1 \%(12 / 21)$ cases with no-fluid. There was one case of anterior capsular extension with radial tear in no-fluid group only $(P=1.00)$.

The mean diameter of the capsulorhexis was $5.3 \pm 0.3 \mathrm{~mm}$ in the fluid group and $5.4 \pm 0.4 \mathrm{~mm}$ in the no-fluid group ( $P=0.7$, difference: -0.05 [95\% CI: $-0.3,0.2]$ ). The mean circularity index was $0.88 \pm 0.04$ in the fluid group and $0.94 \pm 0.04$ in the no-fluid group $(P$-value $<0.001$, difference: 0.05 [ $95 \%$ CI: $0.02,0.08]$ ). Inadequate coverage of IOL by the capsulorhexis edge was noted in $15.8 \%$ (3/19) cases with fluid and $9.5 \%(2 / 21)$ cases with no-fluid $(P=0.65)$.

\section{Discussion}

The main challenge in phacoemulsification in cases of white cataracts is achieving a continuous curvilinear capsulorhexis. The absence of a red reflex, raised intralenticular pressure, and a fragile anterior capsule complicate the management of white cataracts, and an incomplete capsulorhexis has been reported in $3.85 \%-28.3 \%$ cases of white cataracts. ${ }^{9-12,16}$ An ideal capsulorhexis is a well-centered circular opening with smooth margins and a slightly smaller diameter than the IOL providing $360^{\circ} \mathrm{IOL}$ coverage. Inadequate coverage of IOL may lead to posterior capsular opacification and change in the effective lens position, ${ }^{17}$ whereas an excessively small capsulorhexis may cause anterior capsular contraction. ${ }^{18}$
In our study, reproducible circular capsulotomies were achieved with the help of femtosecond laser, providing adequate IOL coverage in $92.5 \%$ (37/40) of cases. The femtosecond laser-assisted capsulotomies may be of four types based on the pattern of completion..$^{15}$ In our study, Type I free-floating capsulotomies were achieved in 52.5\% (21/40) cases. Type II capsulotomy with microadhesions was observed in 37.5\% (15/40) cases and 10\% (4/40) had Type III capsulotomy with incomplete treatment pattern in 1-2 clock hours. No case had a Type IV capsulotomy. A significantly higher incidence of residual adhesions (Type II and Type III capsulotomies) was observed in the subgroup with release of white milky fluid after femtosecond laser delivery $(P<0.003)$.

The reason for microadhesions/incomplete capsulotomies was the explosive egress of white milky fluid on initiation of the capsulotomy, which obscures the visual field and hampers the subsequent delivery of the laser at the same plane. The release of the intralenticular pressure after initiation of the capsulotomy causes a slight change in the position of the anterior capsular plane and hence may result in the occurrence of incomplete capsulotomy. During the lifting of the capsulotomy flap with the microcapsulorhexis forceps, the areas obscured by the white milky fluid during femtosecond laser application should be carefully assessed, as they are likely to have microadhesions. It is imperative to use trypan blue dye to stain the anterior capsule in all cases to delineate the area of microadhesions or incomplete treatment pattern. In each of these cases, the free edge of the capsulotomy was grasped with the help of microcapsulorhexis forceps and a circumferential motion tracing the capsulotomy margins was performed, which was akin to the maneuver that one does while performing a manual capsulorhexis (Figure 1, Video S1). This crucial step ensures the effective release of the underlying residual adhesions in femtosecond laser-assisted capsulotomies. Despite the presence of microadhesions and incomplete treatment patterns, the continuity and circularity of the capsulotomies was achieved in $97.5 \%$ (39/40) of the eyes.

The incidence of incomplete capsulotomies and microadhesions is more in white hypermature cataracts as compared to immature senile cataracts. In a case series of 1,300 cases of senile cataract undergoing FLACS, 96\% capsulotomies were free floating or had small areas of nonperforations. ${ }^{19}$

In our study, one case of anterior capsular extension with radial tear was noted during FLACS. The radial extension occurred while polishing the anterior capsule after IOL implantation (Figure 3). This case was characterized 


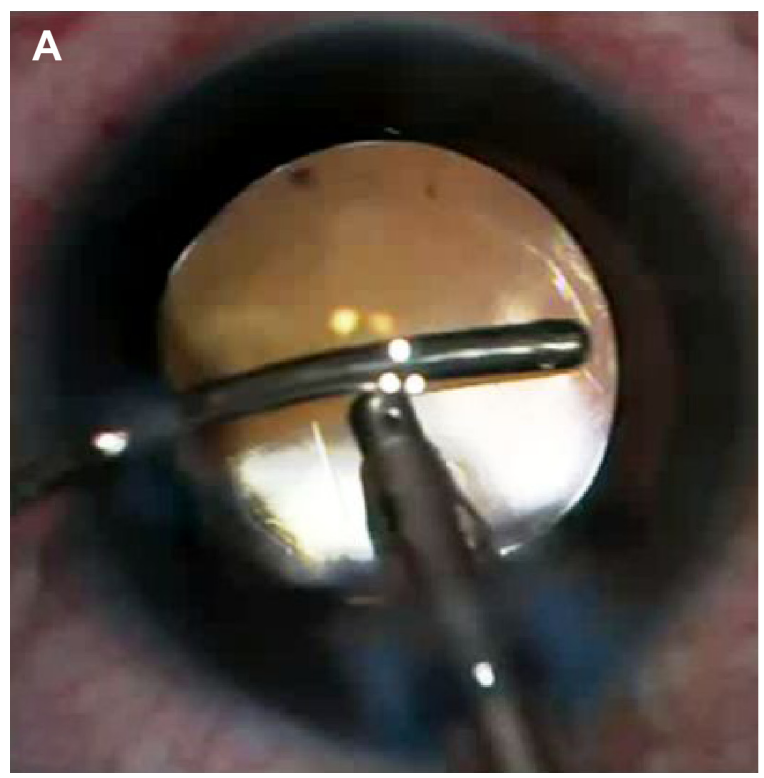

Figure 3 Anterior capsular tear in a case of FLACS.

Notes: (A) Polishing of anterior capsule in a case of FLACS with Type II capsulotomy. capsule (arrow: site of anterior capsular tear with extension).

Abbreviation: FLACS, femtosecond laser-assisted cataract surgery.

by raised intralenticular pressure as evidenced by a gush of white milky fluid after the initial capsulotomy opening and had a Type II capsulotomy with microadhesions. In cases with microadhesions, the capsular edge is fragile and careful anterior capsular polishing is needed to prevent extension and radial tears.

In our experience, a raised intralenticular pressure with release of white milky fluid is the most significant factor affecting the femtosecond laser application. The milky fluid results in microadhesions and incomplete sectors of capsulotomy, which may increase the chances of tear extension during subsequent steps of phacoemulsification. This is in contrast to the manual capsulorhexis where the release of fluid is associated with a subsequent decrease in the intralenticular pressure and more safety in completion of capsulorhexis. A two-stage femtosecond laser capsulotomy has also been described in six cases of intumescent white cataract; however, remnant tissue bridges were present in one-third of the mini-capsulotomies. ${ }^{20}$

In cases undergoing conventional phacoemulsification, a multistep capsulorhexis was performed in $70 \%$ cases to achieve an adequately sized capsulorhexis. The circularity of the capsulorhexis was compromised, more so in cases with release of milky fluid. FLACS eases the process of capsulotomy by ensuring a single-step capsulotomy. Microadhesions if present can be easily released during capsulotomy removal with forceps, without jeopardizing the size, circularity, and continuity of the capsulotomy.

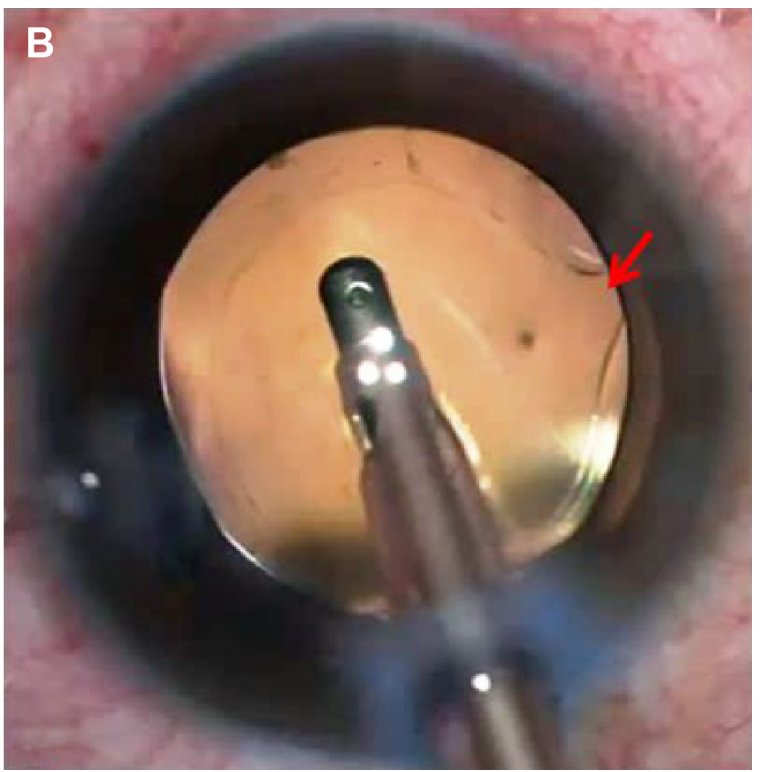

(B) Anterior capsular tear and extension in I clock hour during polishing of anterior A previous study has demonstrated the safety and efficacy of femtosecond laser-assisted capsulotomy in 25 cases of white cataracts, with radial anterior tears in two eyes, an adherent tongue-like capsule adhesion in nine eyes, and an incomplete capsulotomy in three eyes. ${ }^{13}$

The total aspiration time and total surgical duration was longer in FLACS, but the difference between the two groups was not statistically significant. The removal of cortical matter is more difficult in FLACS. A hybrid technique of IA using a combination of coaxial and bimanual IA hand pieces was frequently employed to aspirate the subincisional cortical matter in cases undergoing FLACS, which may explain the longer aspiration times. ${ }^{14}$

\section{Conclusion}

To conclude, femtosecond laser creates single-step, circular, adequately sized capsulotomies and eliminates the difficulty associated with capsulorhexis in white cataracts. The release of white milky fluid during femtosecond laser delivery is the most important factor affecting the creation of a freefloating capsulotomy, and microadhesions and incomplete capsulotomies may be present in up to $47.5 \%$ cases of FLACS. There is no significant difference in terms of the intraoperative complications and the final visual outcome between FLACS and conventional phacoemulsification. To the best of our knowledge, this is the first prospective study comparing conventional phacoemulsification with FLACS in white cataracts in terms of intraoperative parameters and 
postoperative outcomes. Further randomized control trials with a larger sample size should be undertaken to further evaluate the long-term superiority of femtosecond laser over conventional phacoemulsification.

\section{Author contributions}

All authors meet the authorship criteria as listed:

1. substantial contributions to conception and design, acquisition of data, or analysis and interpretation of data;

2. drafting the article or revising it critically for important intellectual content;

3. final approval of the version to be published; and

4. agreement to be accountable for all aspects of the work in ensuring that questions related to the accuracy or integrity of any part of the work are appropriately investigated and resolved.

\section{Disclosure}

The authors report no conflicts of interests in this work.

\section{References}

1. Nagy Z, Takacs A, Filkorn T, Sarayba M. Initial clinical evaluation of an intraocular femtosecond laser in cataract surgery. J Refract Surg. 2009;25:1053-1060.

2. Masket S, Sarayba M, Ignacio T, Fram N. Femtosecond laser-assisted cataract incisions: architectural stability and reproducibility. $J$ Cataract Refract Surg. 2010;36:1048-1049.

3. Kránitz K, Takacs A, Miháltz K, et al. Femtosecond laser capsulotomy and manual continuous curvilinear capsulorhexis parameters and their effects on intraocular lens centration. $J$ Refract Surg. 2011;27:558-563.

4. Conrad-Hengerer I, Hengerer FH, Schultz T, Dick HB. Effect of femtosecond laser fragmentation on effective phacoemulsification time in cataract surgery. J Refract Surg. 2012;28:879-883.

5. Chen M, Swinney C, Chen M. Comparing the intraoperative complication rate of femtosecond laser-assisted cataract surgery to traditional phacoemulsification. Int J Ophthalmol. 2015;8:201-203.
6. Chen X, Xiao W, Ye S, Chen W, Liu Y. Efficacy and safety of femtosecond laser-assisted cataract surgery versus conventional phacoemulsification for cataract: a meta-analysis of randomized controlled trials. Sci Rep. 2015;5:13123.

7. Abell RG, Kerr NM, Vote BJ. Femtosecond laser-assisted cataract surgery compared with conventional cataract surgery. Clin Experiment Ophthalmol. 2013;41:455-462.

8. Brazitikos PD, Tsinopoulos IT, Papadopoulos NT, Fotiadis K, Stangos NT. Ultrasonographic classification and phacoemulsification of white senile cataracts. Ophthalmology. 1999;106:2178-2183.

9. Bhattacharjee K, Bhattacharjee H, Goswami BJ, Sarma P. Capsulorhexis in intumescent cataract. J Cataract Refract Surg. 1999;25:1045-1047.

10. Jacob S, Agarwal A, Agarwal A, et al. Trypan blue as an adjunct for safe phacoemulsification in eyes with white cataract. $J$ Cataract Refract Surg. 2002;28:1819-1825.

11. Kara-Junior N, de Santhiago MR, Kawakami A, Carricondo P, Hida WT. Mini-rhexis for white intumescent cataracts. Clinics. 2009; 64:309-312.

12. Vajpayee RB, Bansal A, Sharma N, Dada T, Dada VK. Phacoemulsification of white hypermature cataract. J Cataract Refract Surg. 1999;25: $1157-1160$.

13. Conrad-Hengerer I, Hengerer FH, Joachim SC, Schultz T, Dick HB. Femtosecond laser-assisted cataract surgery in intumescent white cataracts. J Cataract Refract Surg. 2014;40:44-50.

14. Agarwal T, Jhanji V, Gopalakrishnan K, Khokhar SK, Dada T, Panda A. Hybrid bimanual technique for aspiration of residual cortex. Acta Ophthalmol. 2012;90:e236-e237.

15. Nagy ZZ, Takacs AI, Filkorn T, et al. Complications of femtosecond laser-assisted cataract surgery. J Cataract Refract Surg. 2014;40: 20-28.

16. Chakrabarti A, Singh S, Krishnadas R. Phacoemulsification in eyes with white cataract. J Cataract Refract Surg. 2000;26:1041-1047.

17. Ravalico G, Tognetto D, Palomba M, Busatto P, Baccara F. Capsulorhexis size and posterior capsule opacification. J Cataract Refract Surg. 1996;22:98-103.

18. Sugimoto Y, Takayanagi K, Tsuzuki S, Takahashi Y, Akagi Y. Postoperative changes over time in size of anterior capsulorrhexis in phacoemulsification/aspiration. Jpn J Ophthalmol. 1998;42:495-498.

19. Roberts TV, Lawless M, Bali SJ, Hodge C, Sutton G. Surgical outcomes and safety of femtosecond laser cataract surgery: a prospective study of 1500 consecutive cases. Ophthalmology. 2013;120:227-233.

20. Schultz T, Dick HB. Laser-assisted mini-capsulotomy: a new technique for intumescent white cataracts. J Refract Surg. 2014;30:742-745.
Clinical Ophthalmology

\section{Publish your work in this journal}

Clinical Ophthalmology is an international, peer-reviewed journal covering all subspecialties within ophthalmology. Key topics include: Optometry; Visual science; Pharmacology and drug therapy in eye diseases; Basic Sciences; Primary and Secondary eye care; Patient Safety and Quality of Care Improvements. This journal is indexed on

\section{Dovepress}

PubMed Central and CAS, and is the official journal of The Society of Clinical Ophthalmology (SCO). The manuscript management system is completely online and includes a very quick and fair peer-review system, which is all easy to use. Visit http://www.dovepress.com/ testimonials.php to read real quotes from published authors. 